\title{
Preoperative Th1/Th2 and related cytokines: Prediction value in postoperative febrile UTI after ureteroscopy in patients with ureteral calculi
}

\author{
Zhen Li ${ }^{A}$, Kang-Er Wang ${ }^{B, C}$, Xie-Lai Zhou ${ }^{C, D}$, Jin Zhou ${ }^{D, E}$, Chun-Hua Ye ${ }^{F}$ \\ Department of Urology, Affiliated Hospital of Hangzhou Normal University, China \\ A - research concept and design; $\mathrm{B}$ - collection and/or assembly of data; $\mathrm{C}$ - data analysis and interpretation; \\ $D$ - writing the article; $E$ - critical revision of the article; $F$ - final approval of the article
}

Address for correspondence

Chun-Hua Ye

E-mail:Chun_Hua_Ye@163.com

Funding sources

None declared

Conflict of interest

None declared

Received on May 6, 2017

Reviewed on March 4, 2018

Accepted on August 9, 2018

Published online on November 28, 2018

Cite as

Li Z, Wang K-E, Zhou X-L, Zhou J, Ye C-H. Preoperative Th1/Th2 and related cytokines: Prediction value in postoperative febrile UTI after ureteroscopy in patients with ureteral calculi. Adv Clin Exp Med. 2019;28(1):125-132. doi:10.17219/acem/94157

DOI

10.17219/acem/94157

\section{Copyright}

Copyright by Author(s)

This is an article distributed under the terms of the

Creative Commons Attribution Non-Commercial License

(http://creativecommons.org/licenses/by-nc-nd/4.0/)

\begin{abstract}
Background. The topic of whether preoperative Th1/Th2 cells and their related factors have a predictive value for postoperative febrile urinary tract infection (UTI) in patients with ureteral calculi has not been explored.

Objectives. The objective of this study was to investigate the role of preoperative Th1/Th2 cells and related cytokines in the prediction of postoperative febrile UTI after ureteroscopy in patients with ureteral calculi.

Material and methods. One hundred sixty patients who underwent ureteroscopic pneumatic lithotripsy in the Affiliated Hospital of Hangzhou Normal University (China) were recruited and divided into febrile UTI group $(n=78)$ and non-UTI group $(n=82)$. Flow cytometry was used to detect the proportions of Th1 and Th2 cells (Th1\% and Th2\%). Detection of Th1/Th2 cell-related cytokines was conducted using enzyme-linked immunosorbent assay (ELISA). Quantitative real-time polymerase chain reaction (qRT-PCR) was applied to measure the expression of $\mathrm{T}$-bet and GATA3.
\end{abstract}

Results. Compared with patients in non-UTI group, those in febrile UTI group had significantly increased proportions of Th2 cells, levels of Th2 cytokines (interleukin (IL)-4, IL-10 and IL-5), and mRNA expression of Th2-associated transcription factor GATA3 (all $\mathrm{p}<0.05$ ). In addition, the Th1/Th2 ratio of febrile UTI group was significantly lower than that of non-UTI group ( $p<0.001)$. Receiver operating characteristic (ROC) curve analysis showed that the accuracy rate of Th2\%, Th1/Th2 ratio, and IL-4, IL-10 and LL-5 levels for the diagnosis of postoperative febrile UTI in patients with ureteral calculi was $90.63 \%, 85.00 \%, 72.50 \%, 87.50 \%$, and $91.88 \%$, respectively, and their combined diagnostic sensitivity was $97.4 \%$ with specificity as high as $100 \%$.

Conclusions. Perioperative Th2 dominance was correlated with the risk of postoperative febrile UTI after ureterscopy in patients with ureteral calculi, which can provide clinical guidance for the development of individualized treatment.

Key words: Th1/Th2, ureteral calculi, febrile urinary tract infection 


\section{Introduction}

Urinary calculus is the most common acute disease in urology surgery, seen in approx. $15 \%$ of the population, and is responsible for $20 \%$ of cases of urolithiasis. ${ }^{1,2} \mathrm{~Pa}$ tients with ureteral calculi often develop renal or ureteral colic, leading to severe pain in the waist or midsection accompanied by other symptoms such as nausea, vomiting and hematuria, seriously affecting the quality of life. ${ }^{3} \mathrm{With}$ the advancement of ureteroscopic technologies, treatments for the removal of ureteral calculi have shown decreased procedural invasiveness with high success rates and limited morbidity. ${ }^{4}$ In their paper, de la Rosette et al. analyzed 11,885 ureteral calculi patients treated with ureteroscopy and revealed that the stone-free rate and postoperative complication rate were $85.6 \%$ and $3.5 \%$, respectively, ${ }^{5}$ suggesting that ureteroscopy can be used in patients with larger and more complicated stones, as well as elderly patients with significant comorbidities. ${ }^{4}$ However, the incidence of severe complications is still high after ureteroscopy treatment, including febrile urinary tract infection (UTI). Therefore, it is urgent to explore factors that may affect the postoperative occurrence of febrile UTI to provide a new therapeutic target for the treatment of ureteral calculi.

$\mathrm{CD} 4^{+} \mathrm{T}$ cells can be classified into Th1 and Th 2 subsets based on the cytokines secreted in long-term cultured murine cells that mediate immune functions. ${ }^{6}$ Recently, many studies have found that Th1 and Th2 cells have different effects on immune responses. ${ }^{7,8}$ Specifically, Th1 cells can produce interferon- $\gamma$ (IFN- $\gamma$ ) and interleukin-2 (IL-2), as well as tumor necrosis factor- $\alpha$ (TNF- $\alpha$ ) to regulate cellular immunity; additionally, Th2 cells can promote the differentiation and response of Th1 cells, secrete IL-4, IL-10, and IL-5, and regulate humoral immunity. ${ }^{9,10}$ Furthermore, Th1 and Th2 cells cross-inhibit each other and produce different cytokines to maintain the balance of the immune response. ${ }^{11,12}$ The occurrence and progression of infectious diseases are closely associated with Th1/Th2 cells and related cytokines. For instance, Kang et al. found that the concentration ratio of Th1/Th2 cytokines in patients co-infected with $\mathrm{HIV} / \mathrm{HCV}$ was apparently higher than in patients infected only with HCV or without infection, but significantly lower than in patients infected only with HIV. ${ }^{13}$ Tang et al. revealed that children with fevers had higher levels of IL-4, IL-6, IL-10, TNF- $\alpha$, and IFN- $\gamma$ than healthy controls, and their cytokine levels were also different from those with hemophagocytic lymphohistiocytosis (HLH) or viral infection. ${ }^{14}$ Additionally, they demonstrated that the patients with microbiologically documented infection (MDI) had much higher IL-6 levels than HLH patients, and the IFN- $\gamma$ levels were only slightly increased in MDI patients. In the intestinal mucosa of patients with postinfectious irritable bowel syndrome, the IFN- $\gamma$ levels were upregulated, while IL-10 levels were downregulated, suggesting that infection may break the balance between Th1 and Th2 cells. ${ }^{15}$ Meanwhile, it was reported that serum
Th1/Th2 cytokines may be conducive to the prediction of prognosis and selection of target therapies for patients with Kawasaki disease. ${ }^{16}$ These studies indicated that a Th1/Th2 imbalance exists in many infectious diseases and affects the outcome and prognosis of diseases. However, it has not been explored whether preoperative Th1/Th2 cells and their related factors have predictive value for postoperative febrile UTI in patients with ureteral calculi.

Therefore, 160 cases were recruited in this study before receiving ureteroscopic pneumatic lithotripsy; after treatment, the patients were divided into 2 groups depending on the presence of postoperative febrile UTI: UTI group $(\mathrm{n}=78)$ and non-UTI group $(\mathrm{n}=82)$. Flow cytometry was used to measure the proportions of Th1 and Th2 cells. Enzyme-linked immunosorbent assay (ELISA) was utilized to detect the levels of Th1/Th2-related cytokines. The expression levels of Th1/Th2-related transcription factors T-bet and GATA3 were determined using quantitative realtime polymerase chain reaction (qRT-PCR). This data was used to analyze the value of preoperative Th1/Th2 cells and related cytokines in the prediction of postoperative febrile UTI in patients with ureteral calculi.

\section{Material and methods}

\section{Ethics statement}

This study was approved by the Ethics Committee of the Affiliated Hospital of Hangzhou Normal University (China) and was conducted in strict accordance with the Declaration of Helsinki. ${ }^{17}$ Additionally, informed consent was obtained from each participant prior to the study.

\section{Subjects}

From December 2009 to December 2016, 160 patients with ureteral stones diagnosed by kidney-ureter-bladder (KUB) X-ray, intravenous urography (IVP), color Doppler ultrasound, computed tomography (CT), and magnetic resonance (MR) urography at the Affiliated Hospital of Hangzhou Normal University were recruited as subjects of this study. After receiving ureteroscopic pneumatic lithotripsy, 160 patients were divided into 2 groups based on the presence of postoperative febrile UTI at any point postoperatively during the follow-up. Among them, 78 patients had postoperative febrile UTI (UTI group), including 49 men and 29 women, whose age range was 16-90 years (mean age $55.14 \pm 21.90$ years); the other 82 patients who did not have postoperative febrile UTI (non-UTI group) comprised of 55 men and 27 women with an age range of $17-88$ years (mean age $52.51 \pm 20.97$ years). Postoperative febrile UTI was defined as a body temperature higher than $38^{\circ} \mathrm{C} .^{18}$ The inclusion criteria were as follows: all patients had undergone ureteroscopic pneumatic lithotripsy; all patients had received prophylactic antibiotics according to physicians' discretion, consisting of second generation 
cephalosporin (7 days) and metronidazole (5 days) intravenously; all patients had no chills, shivers, fever, or any acute infection history such as urinary irritation symptoms approx. 2 weeks before the operation; each case was confirmed with sufficient clinical examinations. The exclusion criteria were as follows: patients with a history of immune system diseases such as diabetes, Crohn's disease, systemic lupus erythematosus, rheumatoid arthritis, and rheumatoid disease; patients with other immune diseases, including severe liver and kidney diseases, cardiovascular and cerebrovascular diseases and severe infections; patients with a malignant tumor; patients with a recent history of using immune agent use; and pregnant and lactating women. Blood samples from patients were drawn in the morning before ureteroscopic pneumatic lithotripsy.

\section{Ureteroscopic pneumatic lithotripsy}

Patients were placed in the lithotomy position for epidural block anesthesia. The ureteroscope (DUR-D Gyrus ACMI, Southborough, USA) was inserted into the ureter from the external ureteral orifice of the patients. During the process, an F4 safety guide wire was slowly inserted from the diseased ureter, and a hydraulic pump was used to expand the ureteral orifice. The ureteroscope was gradually pushed to reach the stones. The size, movement and incarceration of the stones were observed to confirm the feasibility of the operation. Next, the ureteroscope was removed, and the probe for ureteroscopic pneumatic lithotripsy was inserted from the ureteral passage to smash the stones. Stones with a small diameter were discharged with urine, and those with a larger diameter $(>3 \mathrm{~mm})$ were removed with a stone basket or stone forceps. It was very important to avoid injury of the ureteral mucosa during the stone removal procedure. The large stones from patients with inflammatory polyps were sent to the pathology department for further examination. In all cases, the procedures were carried out by 2 experienced urologists. All the patients were followed up utilizing outpatient assessments and telephone contact within a 1-month period.

\section{Measurement of indexes}

In the cases of multiple stones, the stone size was calculated by the total diameter of the stone cluster. The criterion of being stone-free was no obvious stones or stones less than $2 \mathrm{~mm}$ in diameter detected using X-ray or ultrasound examination at 1 month after ureteroscopy. Additionally, pyuria indicated 10 or more white blood cells per highpower field (HPF).

\section{Flow cytometry}

Approximately $200 \mu \mathrm{L}$ of peripheral blood was added into RPMI 1640 medium $(200 \mu \mathrm{L})$. Next, $19 \mu \mathrm{L}$ of $1 \mu \mathrm{g} / \mathrm{mL}$ phorbol 12-myristate 13-acetate (PMA) solution, $6 \mu \mathrm{L}$ of $50 \mu \mathrm{g} / \mathrm{mL}$ lincomycin solution and $6 \mu \mathrm{L}$ of monensin solution were added subsequently to a uniform level to culture for $5 \mathrm{~h}$ at $37^{\circ} \mathrm{C}$. Later, $100 \mu \mathrm{L}$ of the incubated cell suspension was added into a flow cytometer, and CD4-FITC and CD8-APC monoclonal antibodies were added for $15 \mathrm{~min}$ under dark-light reaction at room temperature. Next, the cells were washed twice with phosphate-buffered saline (PBS), and then, $100 \mu \mathrm{L}$ of membrane breaking agent was added for $15 \mathrm{~min}$ at room temperature. The cells were then washed twice again with PBS before adding IFN- $\gamma$-PE-CY5 and IL-4-PE monoclonal antibodies for $20 \mathrm{~min}$ at room temperature under dark-light reaction. The cells were resuspended with $300 \mu \mathrm{L}$ of PBS after washing twice with PBS. Next, FACS CANTO II flow cytometry was used to detect the proportions of Th1 and Th2 cells and the levels of CD4 ${ }^{+}$ and $\mathrm{CD}^{+} \mathrm{T}$ cells.

\section{ELISA}

Serum separated from $2 \mathrm{~mL}$ of venous blood was examined using ELISA. The contents of IL-2, IL-4, IL-5, IL-10, IFN- $\gamma$, and TNF- $\alpha$ were determined in strict accordance with the instructions for each ELISA kit (Shanghai Westang Biotechnology Co., Ltd., Shanghai, China).

\section{qRT-PCR}

Total RNA from PBMCs was extracted strictly following the manufacturer's instructions (RNeasy mini kit; Qiagen, Tokyo, Japan). cDNA synthesis was conducted using the T-Primed First-Strand Kit for qRT-PCR (Amersham Biosciences United Kingdom, Little Chalfont, UK). Additionally, the expression levels were determined with qRT-PCR using the Light Cycler-Fast Start DNA Master SYBR Green I kit (Roche Diagnostics, Mannheim, Germany). Based on the gene sequences published in the GenBank database, the primers were designed using the Primer v. 5.0 software and were synthesized by Shanghai Sangon Biotechnology Co. Ltd. (Shanghai, China; Table 1). The qRT-PCR conditions were as follows: denaturation at $95^{\circ} \mathrm{C}$ for $10 \mathrm{~min}$, then 45 cycles of denaturation at $95^{\circ} \mathrm{C}$ for $10 \mathrm{~s}$, annealing for $10 \mathrm{~s}$ (at $58^{\circ} \mathrm{C}$ for T-bet and $60^{\circ} \mathrm{C}$ for GATA3), and extension at $72^{\circ} \mathrm{C}$ for $7 \mathrm{~s}$. The internal reference gene GAPDH was also treated under the aforementioned conditions, except that its extension was at $72^{\circ} \mathrm{C}$ for $8 \mathrm{~s}$. The ratio of the gene expression levels was calculated using the $2^{-\Delta \Delta \mathrm{Ct}}$ method.

Table 1. Primer sequences for qRT-PCR

\begin{tabular}{|c|c|c|}
\hline \multirow{2}{*}{ Gene } & Primer & Sequences \\
\hline \multirow{2}{*}{ GATA3 } & forward & 5'-CTGGCCACAGTTGTTTCATG-3' \\
\cline { 2 - 3 } & reverse & 5'-GCAACTGGTGAACGGTAACA-3' \\
\multirow{2}{*}{ T-bet } & forward & 5'-GTCAATTCCTTGGGGGAGAT-3' \\
\cline { 2 - 3 } & reverse & 5'-TCATGCTGACTGCTCGAAAC-3' \\
\multirow{2}{*}{ GAPDH } & forward & 5'-ACCCAGAAGACTGTGGATGG-3' \\
& reverse & 5'-TTCTAGACGGCAGGTCAGGT-3' \\
\hline
\end{tabular}




\section{Statistical methods}

All statistical data was analyzed using SPSS v. 22.0 software (IBM Corp., Armonk, USA). The measurement data was presented as means \pm standard deviation $( \pm S D)$. The Kolmogorov-Smirnov test was used to analyze the normal distribution, and the measurement data consistent with a normal distribution was analyzed using a Student's t-test. Enumeration data was analyzed using a $\chi^{2}$ test. The results of clinical experiments were plotted on a receiver operating characteristic (ROC) curve, and the area under the curve and 95\% confidence intervals (95\% CIs) were calculated to predict febrile UTI after ureteroscopic pneumatic lithotripsy. The value of $p<0.05$ was regarded as significantly different.

\section{Results}

\section{Comparison of the characteristics and surgical outcomes between the 2 groups}

As shown in Table 2, no differences were found in the age, sex, BMI index, pyuria, preoperative ureteral stent, and levels of C-reactive protein (CRP) and procalcitonin (PCT), mean time from the first visit to surgery and operation time (all $\mathrm{p}>0.05$ ). In addition, the 2 groups of patients showed no obvious differences in the number of stones, stone size, operative time, and number of residual stones (all $\mathrm{p}>0.05$ ).

Table 2. The characteristics and surgical outcomes in non-UTI group and UTI group

\begin{tabular}{|c|c|c|c|c|}
\hline Parameters & Number of patients & non-UTI $(n=82)$ & UTI $(n=78)$ & $\mathrm{p}$-value \\
\hline $\begin{array}{l}\text { Age [years] } \\
<65 \\
\geq 65\end{array}$ & $\begin{array}{c}103 \\
57\end{array}$ & $\begin{array}{l}56 \\
26\end{array}$ & $\begin{array}{l}47 \\
31\end{array}$ & 0.324 \\
\hline $\begin{array}{l}\text { Gender } \\
\text { male } \\
\text { female }\end{array}$ & $\begin{array}{c}104 \\
56\end{array}$ & $\begin{array}{l}55 \\
27\end{array}$ & $\begin{array}{l}49 \\
29\end{array}$ & 0.621 \\
\hline $\begin{array}{l}\text { Body mass index } \\
\quad<30 \\
\geq 30\end{array}$ & $\begin{array}{c}142 \\
18\end{array}$ & $\begin{array}{c}75 \\
7\end{array}$ & $\begin{array}{l}67 \\
11\end{array}$ & 0.321 \\
\hline Mean time from diagnosis to treatment [days] & 160 & $20.00 \pm 5.02$ & $21.05 \pm 2.98$ & 0.131 \\
\hline $\begin{array}{l}\text { CRP }[\mathrm{mg} / \mathrm{L}] \\
<6 \\
6 \sim 18 \\
>18\end{array}$ & $\begin{array}{l}74 \\
29 \\
57\end{array}$ & $\begin{array}{l}40 \\
15 \\
27\end{array}$ & $\begin{array}{l}34 \\
14 \\
30\end{array}$ & 0.749 \\
\hline $\begin{array}{l}\text { PCT }[\mathrm{ng} / \mathrm{mL}] \\
\quad>0.1 \\
\leq 0.1\end{array}$ & $\begin{array}{l}46 \\
114\end{array}$ & $\begin{array}{l}26 \\
56\end{array}$ & $\begin{array}{l}20 \\
58\end{array}$ & 0.485 \\
\hline $\begin{array}{l}\text { Stone history } \\
\text { no } \\
\text { yes }\end{array}$ & $\begin{array}{l}92 \\
68\end{array}$ & $\begin{array}{l}45 \\
37\end{array}$ & $\begin{array}{l}47 \\
31\end{array}$ & 0.525 \\
\hline $\begin{array}{l}\text { Pyuria } \\
\text { no } \\
\text { yes }\end{array}$ & $\begin{array}{l}76 \\
83\end{array}$ & $\begin{array}{l}41 \\
41\end{array}$ & $\begin{array}{l}35 \\
42\end{array}$ & 0.039 \\
\hline $\begin{array}{l}\text { Preoperative ureteral stent } \\
\text { no } \\
\text { yes }\end{array}$ & $\begin{array}{l}98 \\
62\end{array}$ & $\begin{array}{l}53 \\
29\end{array}$ & $\begin{array}{l}45 \\
33\end{array}$ & 0.418 \\
\hline $\begin{array}{l}\text { Number of stones } \\
\text { single } \\
\text { multiple }\end{array}$ & $\begin{array}{l}93 \\
67\end{array}$ & $\begin{array}{l}51 \\
31\end{array}$ & $\begin{array}{l}42 \\
36\end{array}$ & 0.337 \\
\hline $\begin{array}{l}\text { Stone size }[\mathrm{mm}] \\
\quad<20 \\
\geq 20\end{array}$ & $\begin{array}{l}98 \\
62\end{array}$ & $\begin{array}{l}56 \\
26\end{array}$ & $\begin{array}{l}42 \\
36\end{array}$ & 0.075 \\
\hline $\begin{array}{l}\text { Operative time [min] } \\
<15 \\
\geq 15\end{array}$ & $\begin{array}{l}91 \\
69\end{array}$ & $\begin{array}{l}49 \\
33\end{array}$ & $\begin{array}{l}42 \\
36\end{array}$ & 0.524 \\
\hline $\begin{array}{l}\text { Residual stones } \\
\text { no } \\
\text { yes }\end{array}$ & $\begin{array}{l}137 \\
23\end{array}$ & $\begin{array}{c}73 \\
9\end{array}$ & $\begin{array}{l}64 \\
14\end{array}$ & 0.262 \\
\hline
\end{tabular}

UTI - urinary tract infection. 


\section{Comparison of the peripheral blood T-cell subsets and $\mathrm{Th} 1 / \mathrm{Th} 2$ ratio between the 2 groups}

As shown in Table 3, no significant difference was found between the 2 groups of patients in terms of the white blood cell and lymphocyte distribution (both $\mathrm{p}>0.05$ ). Compared with patients in the non-UTI group, those in the febrile UTI group showed increased proportions of Th 2 cells (Th2\%) in peripheral blood (3.43 \pm 1.02 vs $1.63 \pm 0.44, \mathrm{t}=14.620 ; \mathrm{p}<0.001)$ and a decreased Th1/Th2 ratio (7.21 \pm 2.98 vs $14.94 \pm 6.91, \mathrm{t}=9.106$; $\mathrm{p}<0.001)$, but their proportions of Th1 cells (Th1\%) showed no significant difference (22.01 \pm 5.75 vs $22.35 \pm 4.87$; $\mathrm{p}=0.224$ ) (Fig. 1).

\section{Expression of Th1/Th2-related cytokines and associated transcription factors in the 2 groups}

As shown in Fig. 2, compared with patients in the nonUTI group, patients in the febrile UTI group showed no difference in the levels of Th1 cytokines (IL-2, IFN- $\gamma$ and TNF- $\alpha$ ) in the peripheral blood (all p $>0.05$ ), but their Th2 cytokines were remarkably upregulated (IL-4: $4.37 \pm 0.92$ vs $3.61 \pm 0.47$; IL-10: $3.53 \pm 0.75$ vs $2.43 \pm 0.35$; IL-5: 4.76 \pm 0.41 vs $3.04 \pm 0.19$ (all p < 0.05). Additionally, the mRNA expression of T-bet, as a Th1-associated transcription factor, in febrile UTI patients was not different from that in the non-UTI group ( $\mathrm{p}>0.05$ ), but the mRNA expression of GATA3, namely, a Th2-associated transcription factor, was markedly upregulated in patients in the febrile UTI group ( $<<0.05$; Fig. 3).
A

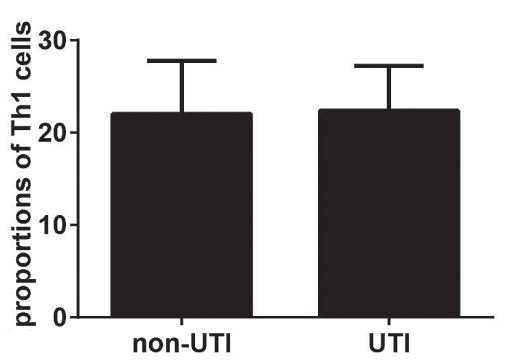

B

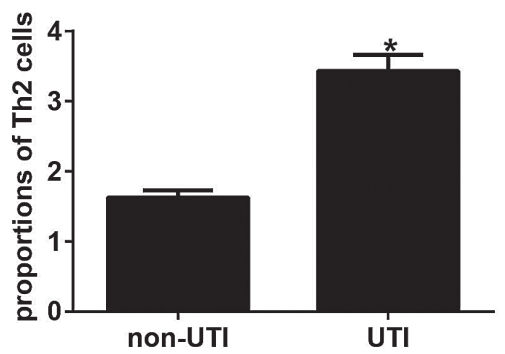

C

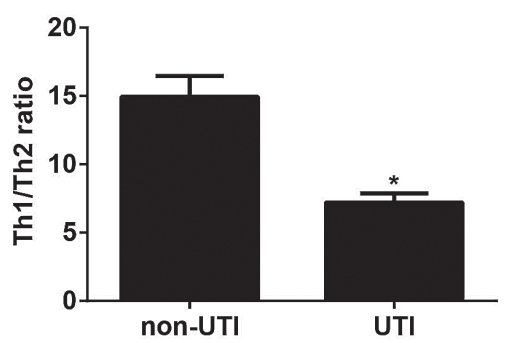

Fig. 1. Proportions of Th1 cells (A) and Th2 cells (B), as well as the Th1/Th2 ratio (C), in the non-UTI group and UTI group

${ }^{*} p<0.05$ compared with patients in the non-UTI group

A

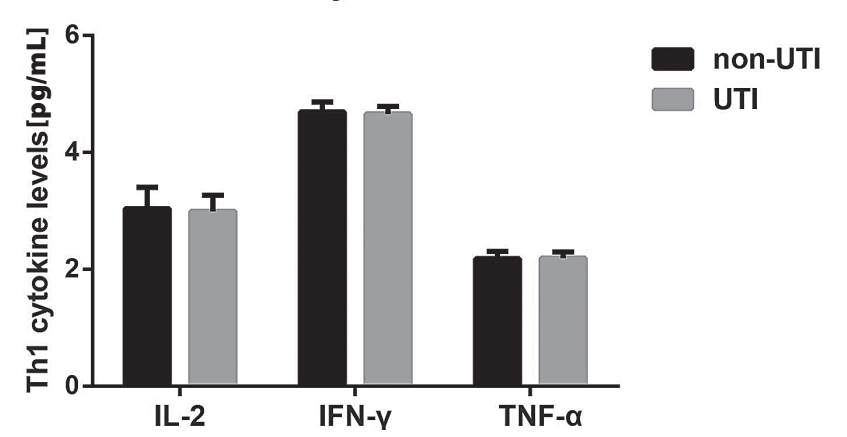

B

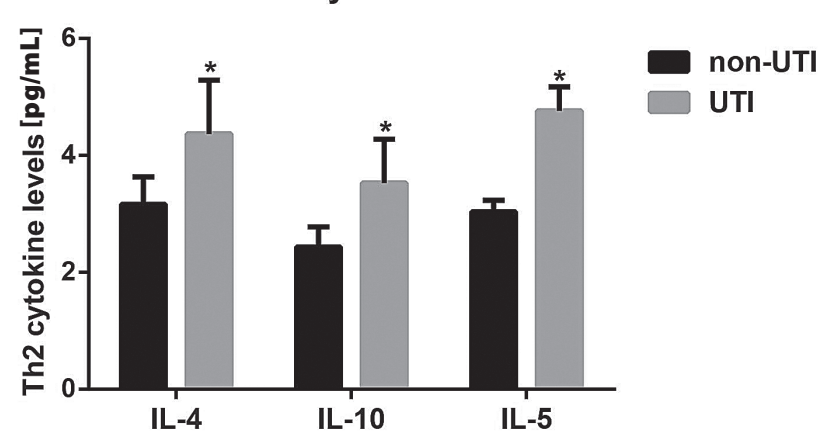

Fig. 2. Levels of Th1/Th2-related cytokines in each group detected using ELISA

A - Th1-related cytokines; B - Th2-related cytokines; ${ }^{*} p<0.05$ compared with patients in the non-UTI group.

Table 3. White blood cell and lymphocyte distribution in non-UTI group and UTI group

\begin{tabular}{|l|c|c|c|}
\multicolumn{1}{|c|}{ Subpopulations } & non-UTI $(\mathrm{n}=82)$ & UTI $(\mathrm{n}=78)$ & Student's t-test \\
\hline Leukocytes [count/L] & $5,626 \pm 1,378$ & $5,401 \pm 879$ & 1.224 \\
\hline Lymphocytes [count/L] & $1,683 \pm 601$ & $1,481 \pm 452$ & 1.801 \\
\hline CD4+ T-lymphocytes [\%] & $46.92 \pm 3.05$ & $47.07 \pm 3.59$ & 0.223 \\
\hline CD8+ T-lymphocytes [\%] & $24.15 \pm 2.99$ & $25.04 \pm 3.04$ & 0.074 \\
\hline CD4/CD8 ratio & $1.97 \pm 0.26$ & $1.91 \pm 0.31$ & 1.867 \\
\hline
\end{tabular}

UTI - urinary tract infection. 


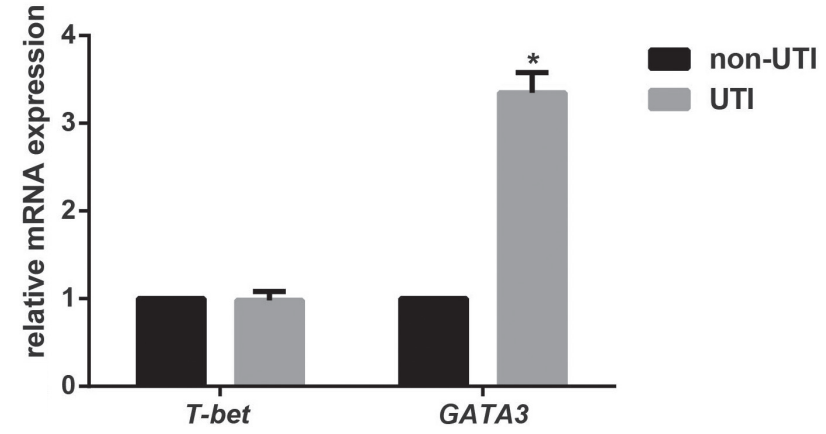

Fig. 3. mRNA expression of Th1/Th2-associated transcription factor T-bet and GATA3 in the non-UTI group and UTI group, as detected using qRT-PCR

${ }^{*} p<0.05$ compared with patients in the non-UTI group.
The predictive value of Th1/Th2 cells and related cytokines for the diagnosis of postoperative febrile UTI in patients with ureteral calculi

Receiver operating characteristic curve analysis was conducted for indexes that were significantly different between the 2 groups, and the results are shown in Fig. 4 and Table 4 . The sensitivity values of Th2\%, the Th1/Th2 ratio, IL-4, IL-10 and IL-5 for the diagnosis of postoperative febrile UTI in patients with ureteral calculi were $87.18 \%, 82.05 \%, 71.79 \%, 76.92 \%$, and $87.18 \%$, respectively. The specificity values were $93.90 \%, 87.80 \%, 73.17 \%, 97.56 \%$,

Table 4. ROC curve analysis of the value of Th2\%, Th1/Th2 ratio, IL-4, IL-10, and IL-5 in predicting postoperative febrile UTI in patients with ureteral calculi

\begin{tabular}{|l|c|c|c|c|c|c|c|c|}
\hline $\begin{array}{l}\text { Th1/Th2 cells and } \\
\text { related cytokines }\end{array}$ & Cut-off & AUC & $95 \%$ Cl & Sensitivity [\%] & Specificity [\%] & PPV [\%] \\
\hline Th2\% & 2.275 & 0.956 & $0.926 ~ 0.986$ & 87.18 & 93.90 & 93.15 \\
\hline Th1/Th2 ratio & 8.742 & 0.897 & $0.849 \sim 0.944$ & 82.05 & 87.80 & 86.49 \\
\hline IL-4 & 3.868 & 0.773 & $0.698 \sim 0.848$ & 71.79 & 73.17 & 71.79 \\
\hline IL-10 & 3.024 & 0.915 & $0.869 \sim 0.961$ & 76.92 & 97.56 & 96.72 \\
\hline IL-5 & 3.381 & 0.943 & $0.904 \sim 0.982$ & 87.18 & 96.34 & 81.63 \\
\hline
\end{tabular}

AUC - area under the ROC curve; CI - confidence interval; PPV - positive predictive value; NPV - negative predictive value.

A

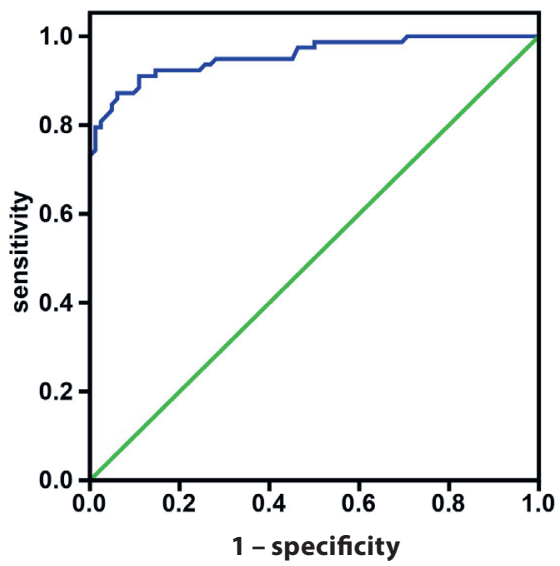

D

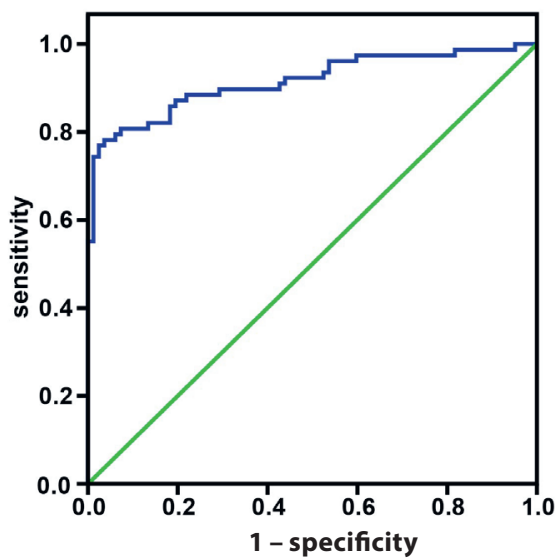

B

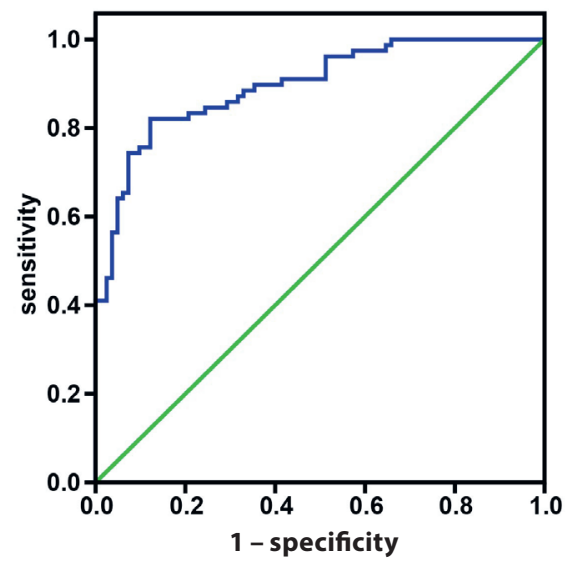

E

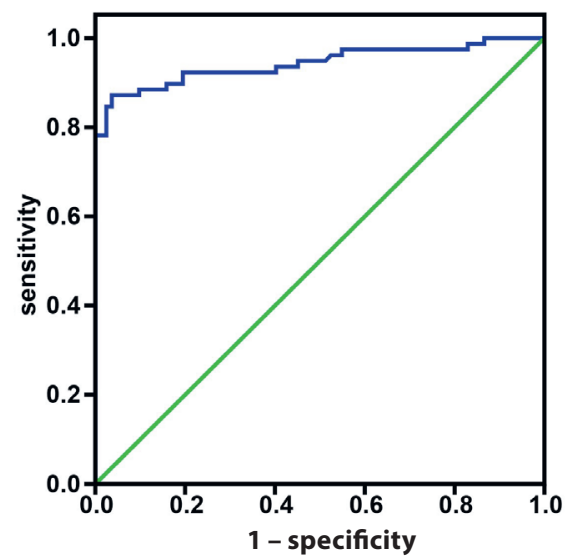

C

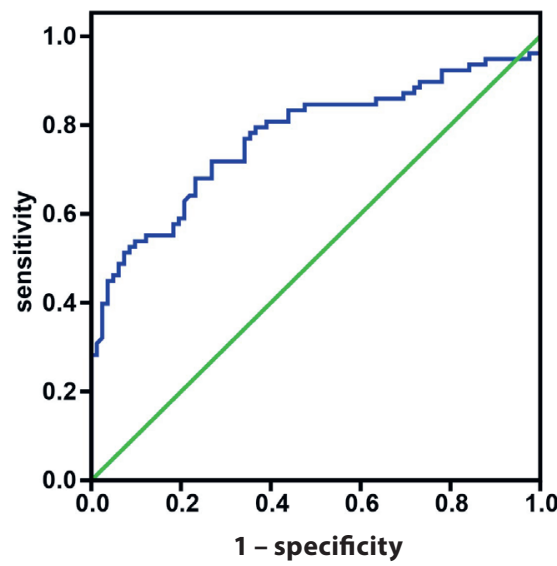

$\mathbf{F}$

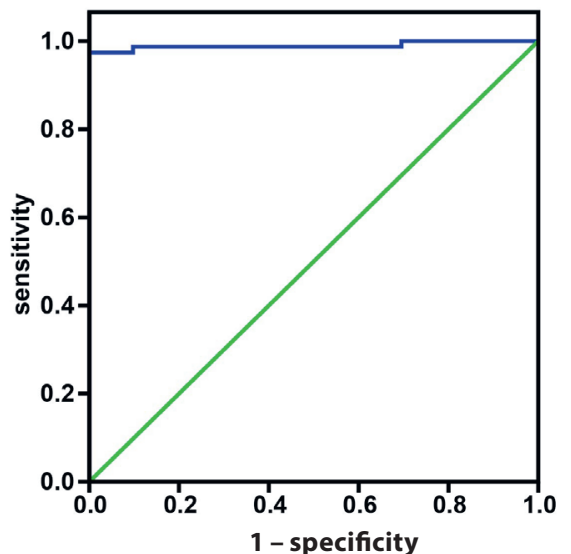

Fig. 4. ROC curve analysis of the value of Th2\% (A), Th1/Th2 ratio (B), IL-4 (C), IL-10 (D), IL-5 (E), and combined indexes (F) for the diagnosis of postoperative febrile UTI in patients with ureteral calculi 
and $96.34 \%$, respectively. The accuracy values were $90.63 \%$, $85.00 \%, 72.50 \%, 87.50 \%$, and $91.88 \%$, respectively. In addition, the sensitivity of the combined diagnosis was $97.4 \%$ with specificity as high as $100 \%$.

\section{Discussion}

The most important finding of this study is that patients with postoperative febrile UTI showed a significantly elevated proportion of Th2 cells without an obvious change in the number of Th1 cells, thus resulting in the reduction of their Th1/Th2 ratio. Under normal circumstances, Th1 and Th2 cells interact and restrict each other to maintain the balance of the immune responses. ${ }^{19}$ When infection occurs, the imbalanced differentiation of Th1 and Th2 cells leads to an abnormal Th1/Th2 ratio. ${ }^{20}$ It has also been reported that infected and non-infected patients showed no notable difference in the proportion of Th1 cells, but the former showed an appreciably higher proportion of Th2 cells, and, thus, a remarkably lower Th1/Th2 ratio than the latter ${ }^{21}$; these previous findings are consistent with our findings and can be explained as postoperative infectious complications being associated with the imbalance of Th1/Th2, particularly inadequate Th2 responses. Additionally, several studies have shown that the Th2 dominance in the Th1/Th2 balance in the human immune system renders patients more susceptible to infections by viruses, protozoa, and intracellular bacteria. ${ }^{22,23}$ However, interestingly, Tatsumi et al. revealed that preoperative Th2 cells are suppressed in infected patients but not in non-infected patients. ${ }^{24}$ On the other hand, Ishikawa et al. reported that no significant difference was observed in the preoperative Th1/Th2 ratio between patients with postoperative complications and those without postoperative complications. ${ }^{25}$ One explanation for the discrepancy in our results may be the difference in background disease.

Cytokines have been recognized as key factors in determining host resistance to infectious pathogens. Specifically, the balance of Th1/Th2 cytokines in hosts is closely related to the prognosis and outcome of infections induced by intracellular microbes. ${ }^{26,27}$ Additionally, the hallmark cytokines of Th1 cells, including IFN- $\gamma$ and lymphotoxin, can activate microbicidal activity, as well as cytokine production in macrophages. ${ }^{28}$ IFN- $\gamma$ signals can also activate a downstream transcription factor, T-bet, to upregulate the expression of genes specific to Th1 cells. ${ }^{29}$ By contrast, IL-4 can enhance the expression level of GATA3, a transcription factor critical for both IL-4 production and Th2 cell differentiation. ${ }^{30}$ To further explore the significance of the Th1/Th2 balance, we used ELISA to determine the expression levels of Th1/Th2 cytokines and applied qRT-PCR to detect the mRNA expression of T-bet and GATA3. We found that patients with postoperative febrile UTI had significantly higher levels of Th2-related cytokines (IL-4, IL-10 and IL-5) and GATA3 than those without postoperative febrile UTI, but no difference was found in the level of Th1-related cytokines (IFN- $\gamma$, IL-2 and TNF- $\alpha$ ) and T-bet. These results further confirmed that the preoperative dominance of Th2 cells in the Th1/Th2 balance may exert a large impact on the occurrence and development of postoperative infection. These findings suggest that the failure of Th2 cells to regulate the Th1 responses or promote the production of antibodies can profoundly affect the host immunity against postoperative infection.

Another important finding of our study was that the preoperative Th2\%, Th1/Th2 ratio, and IL-4, IL-10 and IL-5 values were predictive in postoperative febrile UTI in patients with ureteral calculi with accuracies of $90.63 \%$, $85.00 \%, 72.50 \%, 87.50 \%$, and $91.88 \%$, respectively; the sensitivity of the combined diagnosis was $97.4 \%$ with a specificity as high as $100 \%$. In addition, Tang et al. revealed that the sensitivity and specificity of severe infection prediction were $62.0 \%$ and $85.0 \%$, respectively, when the cut-off value of IL-10 was set at $42.0 \mathrm{pg} / \mathrm{mL} .{ }^{14}$ Additionally, the IL-5 levels were higher than the calculated cut-off value $(11 \mathrm{pg} / \mathrm{mL})$ in 22/37 of patients with perennial allergic rhinitis and $4 / 20$ in the non-atopic healthy controls. ${ }^{31}$ Given the abovementioned results, we may conclude that the preoperative Th2\%, Th1/Th2 ratio and cytokine levels can be used as effective reference indicators for the diagnosis of postoperative febrile UTI in patients with ureteral calculi.

Nevertheless, this study had also some limitations. For instance, the stones in the UTI group were larger than those in the non-UTI group because no statistical difference was revealed between them. Moreover, the stone size could be the risk factor of febrile UTI after ureteroscopy in patients with ureteral calculi. ${ }^{32}$ Additionally, we included patients with pyuria and/or those who used a preoperative ureteral stent, which could be a sign of active inflammation. Thus, to eliminate the effects of other risk factors in the future, we should further expand the sample size, consider more clinical indexes and exclude patients with possible inflammation.

Overall, preoperative Th2 dominance was correlated with postoperative febrile UTI in patients with ureteral calculi. In addition, the preoperative values of the Th2\%, Th1/Th2 ratio, IL-4, IL-10 and IL-5 were good predictive indexes in postoperative febrile UTI in patients with ureteral calculi. These results provide further information that may direct future treatments based on the Th1/Th2 concept focusing on decreasing the risk of postoperative infection.

\section{References}

1. Cheng Y, Liu GL. Current state and advance of flexible ureteroscope in the treatment of upper urinary calculi. J Mod Urol. 2014;5:285-288.

2. Cavildak IK, Nalbant I, Tuygun C, et al. Comparison of flexible ureterorenoscopy and laparoscopic ureterolithotomy methods for proximal ureteric stones greater than $10 \mathrm{~mm}$. Urol J. 2016;13(1): 2484-2489.

3. Korkes F, Gomes SA, Heilberg IP. Diagnosis and treatment of ureteral calculi. J Bras Nefrol. 2009;31:55-61. 
4. El-Qadhi M. Outcome of ureteroscopy for the management of distal ureteric calculi: 5-years' experience. Afr J Urol. 2015;21(1):67-71.

5. de la Rosette J, Denstedt J, Geavlete P, et al; CROES URS Study Group. The clinical research office of the endourological society ureteroscopy global study: Indications, complications, and outcomes in 11,885 patients. J Endourol. 2014;28(2):131-139.

6. Krowka JF, Singh B, Fotedar A, Mosmann T, Giedlin MA, Pilarski LM. $A$ requirement for physical linkage between determinants recognized by helper molecules and cytotoxic T cell precursors in the induction of cytotoxic T cell responses. J Immunol. 1986;136(10):35613566.

7. Feng $\mathrm{Y}$, Tian J, Xie HQ, et al. Effects of acute low-dose exposure to the chlorinated flame retardant dechlorane 602 and Th1 and Th2 immune responses in adult male mice. Environ Health Perspect. 2016; 124(9):1406-1413.

8. Ebrahimian $M$, Hashemi M, Maleki $M$, et al. Induction of a balanced Th1/Th2 immune responses by co-delivery of PLGA/ovalbumin nanospheres and CpG ODNs/PEI-SWCNT nanoparticles as TLR9 agonist in BALB/c mice. Int J Pharm. 2016;515(1-2):708-720.

9. Miyake $\mathrm{K}$, Akahoshi M, Nakashima $\mathrm{H}$. Th subset balance in lupus nephritis. J Biomed Biotechnol. 2011;2011:1-7.

10. Yuan D, Yuan Q, Cui Q, et al. Vaccine adjuvant ginsenoside Rg 1 enhances immune responses against hepatitis $B$ surface antigen in mice. Can J Physiol Pharm. 2016;94(6):676-681.

11. Behfarjam F, Sanati MH, Nasseri Moghaddam S, Ataei M, Nikfam S, Jadali Z. Role of Th1/Th2 cells and related cytokines in autoimmune hepatitis. Turk J Gastroenterol. 2017;28(2):110-114.

12. Wintrob ZA, Hammel JP, Nimako GK, et al. TH1 and TH2 cytokines dataset in insulin users with diabetes mellitus and newly diagnosed breast cancer. Data Brief. 2017;11:331-348.

13. Kang W, Li Y, Zhuang Y, Zhao K, Huang D, Sun Y. Dynamic analysis of Th1/Th2 cytokine concentration during antiretroviral therapy of HIV-1/HCV co-infected patients. BMC Infect Dis. 2012;12:102.

14. Tang $Y$, Liao $C$, Xu X, et al. Evaluation of Th1/Th2 cytokines as a rapid diagnostic tool for severe infection in paediatric haematology/oncology patients by the use of cytometric bead array technology. Clin Microbiol Infect. 2011;17(11):1666-1673.

15. Chen J, Zhang Y, Deng Z. Imbalanced shift of cytokine expression between T helper 1 and T helper 2 (Th1/Th2) in intestinal mucosa of patients with post-infectious irritable bowel syndrome. BMC Gastroenterol. 2012;12:91.

16. Wang $Y$, Wang W, Gong F, et al. Evaluation of intravenous immunoglobulin resistance and coronary artery lesions in relation to Th1/Th2 cytokine profiles in patients with Kawasaki disease. Arthritis Rheum. 2013:65(3):805-814
17. Bădărău DO. Declaration of Helsinki. Phys Ther. 2013:45:1418-1419.

18. Mitsuzuka K, Nakano O, Takahashi N, Satoh M. Identification of factors associated with postoperative febrile urinary tract infection after ureteroscopy for urinary stones. Urolithiasis. 2016;44(3):257-262.

19. Yoon SJ, Kim SJ, Lee SM. Overexpression of HO-1 contributes to sepsis-induced immunosuppression by modulating the Th1/Th2 balance and regulatory T-cell function. J Infect Dis. 2017;215(10):1608-1618.

20. Rubbo PA, Tuaillon E, Bollore $\mathrm{K}$, et al. The potential impact of CD4 ${ }^{+}$ T cell activation and enhanced Th1/Th2 cytokine ratio on HIV-1 secretion in the lungs of individuals with advanced AIDS and active pulmonary infection. Clin Immunol. 2011;139(2):142-154.

21. Matsuda A, Furukawa K, Suzuki H, et al. Does impaired TH1/TH2 balance cause postoperative infectious complications in colorectal cancer surgery? J Surg Res. 2007;139(1):15-21.

22. Del Prete G, Maggi E, Romagnani S. Human Th1 and Th2 cells: Functional properties, mechanisms of regulation, and role in disease. Lab Invest. 1994;70(3):299-306.

23. Romagnani S. The Th1/Th2 paradigm. Immunol Today. 1997;18(6):263.

24. Tatsumi $\mathrm{H}, \mathrm{Ura} \mathrm{H}$, Ikeda $\mathrm{S}$, et al. Surgical influence on $\mathrm{TH} 1 / \mathrm{TH} 2$ balance and monocyte surface antigen expression and its relation to infectious complications. World J Surg. 2003;27(5):522-528.

25. Ishikawa $M$, Nishioka $M$, Hanaki N, et al. Hepatic resection leads to predominance of the T helper-2 lymphocyte phenotype. Hepatol Res. 2004;30:96-103.

26. de Sá KS, Santana BB, de Souza Ferreira TC, et al. IL28B gene polymorphisms and Th1/Th2 cytokine levels might be associated with HTLV-associated arthropathy. Cytokine. 2016;77:79-87.

27. Koguchi Y, Kawakami K. Cryptococcal infection and Th1-Th2 cytokine balance. Int Rev Immunol. 2002;21(4-5):423-438.

28. Suzuki D, Furukawa K, Kimura F, et al. Effects of perioperative immunonutrition on cell-mediated immunity, T helper type 1 (Th1)/Th2 differentiation, and Th17 response after pancreaticoduodenectomy. Surgery. 2010;148(3):573-581.

29. Nosko A, Kluger MA, Diefenhardt $P$, et al. T-Bet enhances regulatory $T$ cell fitness and directs control of th1 responses in crescentic GN. J Am Soc Nephrol. 2017;28(1):185-196.

30. Hercor M, Anciaux M, Denanglaire S, Debuisson D, Leo O, Andris F. Antigen-presenting cell-derived IL- 6 restricts the expression of GATA3 and IL-4 by follicular helper T cells. J Leukoc Biol. 2017;101(1):5-14.

31. Hafez SF, Sallam MM, Ibraheem SA. Local expression of IL-4 and IL-5 in perennial allergic rhinitis and their modulation by topical corticosteroid therapy. Egypt J Immunol. 2004;11(1):111-121.

32. Kato Y, Koseki T, Mastsutani R, et al. MP33-01 risk factors for febrile urinary tract infection after ureteroscopic stone removal. J Urol. 2016; 195(4):e436-e436. 